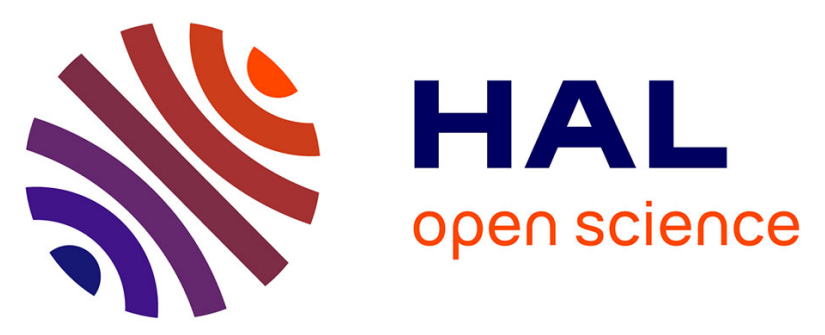

\title{
Photochromic Hybrid Organic-Inorganic Liquid-Crystalline Materials Built from Nonionic Surfactants and Polyoxometalates: Elaboration and Structural Study
}

\author{
Andreas S. Poulos, Doru Constantin, Patrick Davidson, Marianne \\ Impéror-Clerc, Brigitte Pansu, Pierre Panine, Lionel Nicole, Clément Sanchez
}

\section{To cite this version:}

Andreas S. Poulos, Doru Constantin, Patrick Davidson, Marianne Impéror-Clerc, Brigitte Pansu, et al.. Photochromic Hybrid Organic-Inorganic Liquid-Crystalline Materials Built from Nonionic Surfactants and Polyoxometalates: Elaboration and Structural Study. Langmuir, 2008, 24 (12), pp.6285-6291. 10.1021/la8004322 . hal-00338460

\section{HAL Id: hal-00338460 https://hal.science/hal-00338460}

Submitted on 3 Feb 2010

HAL is a multi-disciplinary open access archive for the deposit and dissemination of scientific research documents, whether they are published or not. The documents may come from teaching and research institutions in France or abroad, or from public or private research centers.
L'archive ouverte pluridisciplinaire HAL, est destinée au dépôt et à la diffusion de documents scientifiques de niveau recherche, publiés ou non, émanant des établissements d'enseignement et de recherche français ou étrangers, des laboratoires publics ou privés. 


\section{Photochromic hybrid organic-inorganic liquid-}

\section{crystalline materials built from nonionic surfactants and polyoxometalates: elaboration and structural study}

Andreas S. Poulos, ${ }^{\S}$ Doru Constantin, ${ }^{\S}$ Patrick Davidson,,${ }^{\S}{ }^{*}$ Marianne Impéror, ${ }^{\S}$ Brigitte Pansu, ${ }^{\S}$ Pierre Panine, ${ }^{\#}$ Lionel Nicole, $^{+}$Clément Sanchez ${ }^{+}$

Laboratoire de Physique des Solides, Université Paris Sud, CNRS, UMR 8502, F-91405 Orsay Cedex, France, European Synchrotron Radiation Facility, BP 220, F-38043 Grenoble cedex, France, Chimie de la matière Condensée, UMR 7574 CNRS, Université Pierre et Marie Curie, 4 Place Jussieu, 75005 Paris France.

\section{RECEIVED DATE}

TITLE RUNNING HEAD: Polyoxometalate-doped $\mathrm{L}_{\alpha}$ lamellar mesophase

* Corresponding author. E-mail: davidson@1ps.u-psud.fr. Tel.: +33 (0)1 691553 93. Fax: +33 (0)1 69 156086.

$\S$ CNRS-Université Paris Sud

\# European Synchrotron Radiation Facility

+ CNRS-Université Pierre et Marie Curie 
ABSTRACT. This work reports the elaboration and structural study of new hybrid organic-inorganic materials constructed via the coupling of liquid-crystalline nonionic surfactants and polyoxometalates (POMs). X-ray scattering and polarized light microscopy demonstrate that these hybrid materials, highly loaded with POMs (up to $18 \mathrm{w} \%$ ), are nanocomposites of liquid-crystalline lamellar structure $\left(\mathrm{L}_{\alpha}\right)$, with viscoelastic properties close to those of gels. The interpretation of X-ray scattering data strongly suggests that the POMs are located close to the terminal $-\mathrm{OH}$ groups of the nonionic surfactants, within the aqueous sublayers. Moreover, these materials exhibit a reversible photochromism associated to the photoreduction of the polyanion. The photo-induced mixed-valence behavior has been characterized through ESR and UV-visible-near IR spectroscopies that demonstrate the presence of $\mathrm{W}^{\mathrm{V}}$ metal cations and of the characteristic intervalence charge transfer band in the near-IR region, respectively. These hybrid nanocomposites exhibit optical properties that may be useful for applications involving UV-light sensitive coatings or liquid-crystal based photochromic switches. From a more fundamental point of view, these hybrid materials should be very helpful models for the study of both the static and dynamic properties of nano-objects confined within soft lamellar structures.

KEYWORDS. Hybrid materials, polyoxometalates, surfactants, liquid crystals, self-assembly, photochromism. 


\section{Introduction}

The field of organic-inorganic hybrid materials has mushroomed during the last ten years thanks to the detailed understanding of molecular interactions and to the availability of a large library of building blocks. ${ }^{1}$ Nowadays, molecular approaches to nanomaterials are sophisticated enough for the nanochemists to design numerous molecular species and to elaborate new functional hybrid materials with enhanced properties. Organic-inorganic association represents a creative way to design new materials and compounds for academic research; moreover, their improved or unusual features allow the development of innovative industrial applications. Indeed, in addition to their large diversity in chemical and physical properties and shape, hybrid nanocomposites present the advantage of facilitating both integration and miniaturization, therefore suggesting promising applications in many fields. (Protective and decorative coatings, micro-optics, micro-electronics, ionics and mechanics, functional membranes or barriers, catalysis, sensors, photovoltaic and fuel cells, bioactive hybrids, dental applications, nanocomposites with anti-inflammability properties, etc. ${ }^{2}$ ) Association of inorganic and organic components is also an efficient and useful tool for designing complex nanostructured dense or porous architectures. ${ }^{3}$ Indeed, hybrid materials comprised of surfactants have raised worldwide interest for the production of mesoporous matrices. ${ }^{4}$ In this context, materials scientists have investigated the association of molecular or polymeric surfactants with all kinds of inorganic moieties that can be sol-gel derived oligomers or well-defined NanoBuilding Blocks (NBBs) such as clusters or nanoparticles. ${ }^{5}$

Among NBBs, polyoxometalates (POMs) deserve special attention due to their very well-defined and elegant molecular structures and to their many original physical and chemical properties, which make them interesting compounds for applications in catalysis, electrochemistry, and even in biology. ${ }^{6}$ However, the use of POMs is badly restricted by processing difficulties due to their very large solubility in aqueous solution. This led various teams to produce hybrid materials where POMs are dispersed within, for example, silica or polymer matrices. ${ }^{7}$ The association of the negatively charged POMs with various cationic surfactants was also recently reported by several research groups that employed an 
ionic self-assembly strategy to produce Langmuir-Blodgett films, different kinds of mesophases, and even single crystals. ${ }^{8}$

In this work, we use a different strategy where we dope the lamellar liquid-crystalline $\mathrm{L}_{\alpha}$ phase (i.e. a stack of hydrophobic fluid membranes separated by aqueous regions) of a nonionic commercial surfactant, named Brij30 (essentially $\mathrm{C}_{12} \mathrm{EO}_{4}$, Figure 1a), with large amounts (up to about $18 \mathrm{w} \%$ ) of POMs. Phosphodecatungstic acid $\left[\mathrm{H}_{3} \mathrm{PW}_{12} \mathrm{O}_{40}\right]$ (Figure 1b) was used as the inorganic NBB because it is one of the simplest commercially available POMs, it is extremely soluble in water, and it was the subject of countless reports in the literature. ${ }^{6,9}$ We thus obtained, in a very general way, hybrid materials that combine the interesting electronic properties of POMs with the alignment and processability of liquid-crystalline phases. Here, we describe the elaboration of this doped lamellar mesophase, its molecular organization, and its photo-induced optical properties that may open opportunities for applications involving UV-light sensitive coatings, liquid-crystal based photochromic switches, oxygen sensors, etc.

In contrast with previous work, we associated this inorganic nano-building block with a nonionic surfactant so that the organic-inorganic association is based not on covalent bonding but only on weak interactions such as hydrogen, Van der Waals or solvation bonds. This should allow for better dynamics and therefore let the nanocomposite system reach complete thermodynamic equilibrium with faster kinetics. Moreover, because of the absence of specific interactions, we expect that the features described here should be fairly general to this class of systems.

We report the phase diagram of these hybrid materials as a function of surfactant overall volume fraction in the mixtures, $\phi_{\text {Surf, }}$ and of the POMs volume fraction in the aqueous medium, $\phi_{\mathrm{POM}}$. The diagrams were obtained by performing optical observations in polarized light and small angle X-ray scattering (SAXS) experiments. The localization of the POMs within the lamellar phase was also inferred from the SAXS data. Finally, we followed the UV-induced reduction of the POMs confined within the lamellar phase by Electron Spin Resonance (ESR) and UV-visible-near IR spectroscopic techniques. 


\section{Materials and Methods}

\section{Materials}

The surfactant Brij30 was purchased from Sigma-Aldrich and used without any further purification. It consists mostly of $\mathrm{C}_{12} \mathrm{EO}_{4}$ along with a smaller amount of related $\mathrm{C}_{\mathrm{n}} \mathrm{EO}_{\mathrm{m}}$ molecules. Pure $\mathrm{C}_{12} \mathrm{EO}_{4}$ (Nikkol, 99\%) was also used for comparison. The density of Brij30 is $0.946 \mathrm{~g} . \mathrm{cm}^{-3}$ (according to Sigma-Aldrich); that of $\mathrm{C}_{12} \mathrm{EO}_{4}$ is $0.95 \mathrm{~g} . \mathrm{cm}^{-3}$ (Nikkol). At room temperature, within a given concentration range $(25-85 \mathrm{w} \%)$, aqueous solutions of $\mathrm{C}_{12} \mathrm{EO}_{4}$ were reported to form a lamellar mesophase. $^{10}$

The $\left[\mathrm{PW}_{12} \mathrm{O}_{40}\right]^{3-}$ polyoxometalates were purchased from Sigma-Aldrich either directly in aqueous solution $\left(100 \mathrm{~g} / \mathrm{L}, \phi_{\mathrm{POM}}=1.4 \%\right)$ or in white powder form. These chemicals were used without any further purification. (Purity $99.995 \%$.) The weight proportion of water $(\sim 10 \%)$ in the powder was measured by drying at $150^{\circ} \mathrm{C}$. The volume of each POM is $0.685 \mathrm{~nm}^{3}$ and its molar mass 2880.17 g.mol 1, giving a 'density' for a POM of $6980 \mathrm{Kg} \cdot \mathrm{m}^{-3}$. Thus, for a solution of $\mathrm{M}_{\mathrm{POM}}$ grams of POMs in $\mathrm{M}_{\mathrm{W}}$ grams of water, the volume fraction is given by: $\phi_{P O M}=\frac{V_{p o m}}{V_{p o m}+V_{w}}=\frac{M_{P O M} / \rho_{P O M}}{M_{P O M} / \rho_{P O M}+M_{W} / \rho_{W}}$. The maximum solubility of $\left[\mathrm{PW}_{12} \mathrm{O}_{40}\right]^{3-}$ in water is $200 \mathrm{~g} / 100 \mathrm{ml}$, giving a maximum volume fraction $\left(\phi_{\mathrm{POM}}\right)$ of about $22 \%$. (We have prepared and used a solution with a maximum $\phi_{\text {Ром }}$ of $15 \%$.)

Sample preparation: All samples were prepared in $4 \mathrm{ml}$ tubes. Each tube was rinsed multiple times with Millipore water and then left to dry in an oven. The surfactant was weighed and added first. The

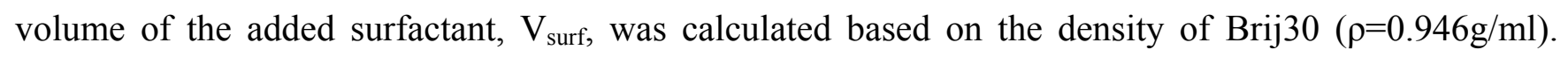
Then for each 'line' of fixed surfactant volume fraction, $\phi_{\text {surf, }}$ the appropriate amount of POM solution, $\mathrm{V}_{\mathrm{aq}}$, was calculated using a simple dilution law $V_{a q}=\left(1 / \phi_{\text {Surf }}-1\right) V_{\text {surf }}$. The correct volume of POMs 
solution was added using a precision micropipette and also weighed to check against its known density. In that way $\phi_{\mathrm{POM}}$ and $\phi_{\text {Surf }}$ were varied from 0 to $20 \%$ and from 5 to $70 \%$, respectively.

After adding all the components, the samples were sealed with parafilm and mixed with a vortexer. Finally they were centrifuged ( $180 \mathrm{~g}, 5$ mins) to collect all material at the bottom of the tube. The samples were stored inside a cupboard to avoid exposure to light and were left to stand for one week before preparation of optical and X-ray capillaries for phase determination. All samples are colorless as long as they are not exposed to UV light. They are visco-elastic liquids. The samples were regularly inspected over up to about a year to notice any evolution with time.

\section{Optical observations}

The mixtures were inspected with the naked eye (in natural light and between crossed polarizers) to assess their homogeneity, the number of phases, and to detect any birefringence. Samples suitable for polarized light microscopy were prepared by gently sucking material with a syringe into flat glass capillary tubes (VitroCom Inc., Mt. Lks, N.J.), 50, 100 or $200 \mu \mathrm{m}$ thick. The capillaries were flamesealed and also stored in the dark. They were examined with an Olympus BX51 polarizing microscope and their textures were photographed using an Olympus (Camedia C-3030) digital camera. The microscope was also equipped with a Mettler FP52 heating stage.

\section{Small-angle $X$-ray scattering}

SAXS experiments were performed both with a laboratory setup and at the ID02 experimental station of the European Synchrotron Radiation Facility. The laboratory setup has already been described in detail ${ }^{11}$. It consists of a rotating $\mathrm{Cu}$ anode generator (Rigaku), graded layer $\mathrm{Ni} / \mathrm{C}$ mirror optics (Osmic), vacuum tubes (inserted between the sample and the detection), and a CCD camera (Princeton). The ID02 beamline, which was also described in detail ${ }^{12}$, allowed us to probe the $0.2-5 \mathrm{~nm}^{-1} \mathrm{q}$-range, where $\mathrm{q}$ is the scattering vector modulus $\mathrm{q}=(4 \pi / \lambda) \sin \theta, \lambda=0.0995 \mathrm{~nm}$ is the wavelength, and $2 \theta$ is the 
scattering angle. Two-dimensional SAXS patterns were recorded using an X-ray image intensifier

coupled to a fast read-out CCD (FreLoN) camera with a typical exposure time of $1 \mathrm{~s}$. Appropriate corrections were carried out and the data were analyzed with Fit2d (ESRF) and Image (LPS, Orsay) softwares. The scattered intensity (in absolute units) was radially averaged to produce 1-dimensional graphs of the scattered intensity versus scattering vector modulus.

For all SAXS experiments, the samples were held in cylindrical Lindemann glass capillaries (MarkRohrchen, Germany) of diameters ranging from 0.5 to $1.0 \mathrm{~mm}$. The capillaries were flame-sealed and submitted to a thermal shock by dipping them in cold water at $0^{\circ} \mathrm{C}$ just before the measurements in order to obtain a completely random "powder" distribution of lamellar phase domains.

\section{Electron Spin Resonance (ESR) experiments}

The ESR experiments were performed with a Bruker Elexsys E500 spectrometer equipped with a SHQ resonator. The ESR spectra were lock-in detected with a modulation of the applied magnetic field at a frequency of $100 \mathrm{kHz}$ and with a $5 \mathrm{G}$ amplitude. The field offset of the electromagnet was measured with a DPPH sample with $g=2.0037 \pm 0.0002$ and is $4.3 \pm 0.4 \mathrm{G}$ for spectra near $\mathrm{g}=2$.

The samples were contained in quartz tubes (diameter of $4 \mathrm{~mm}$ ) and degassed by freeze-pump-thaw cycling. They were exposed to light delivered by a UV lamp (Bioblock Scientific, $\lambda=254 \mathrm{~nm}$, power $30 \mathrm{~W}$ ) for times ranging from 15 minutes to 2 hours in order to produce reduced POM species. They were cooled down with a helium flow ESR900 cryostat from Oxford Instruments.

\section{UV-vis-near IR spectroscopy}

UV-visible spectra were recorded with a Varian Cary 5 spectrophotometer in the 200-2000 nm wavelength range. Samples were held in flat quartz cells of $1 \mathrm{~mm}$ thickness. Photo-reduced samples, exposed to UV-light in the same conditions as above, were measured against a reference pristine sample (i.e. not exposed to UV-light). 


\section{Results}

The phase diagram of this system was mapped out as a function of $\phi_{\mathrm{POM}}$ and $\phi_{\text {Surf, }}$ as shown in Figure 2. A wide single-phase lamellar $\mathrm{L}_{\alpha}$ region was observed, extending up to $\phi_{\mathrm{POM}} \sim 9 \%$ at $\phi_{\text {Surf }}=70 \%$ and to $\phi_{\mathrm{POM}} \sim 4 \%$ at $\phi_{\text {Surf }}=20 \%$ (Figure 3). This phase could only be obtained for $\phi_{\text {Surf }}>20 \%$. The lamellar phase was identified by polarized light microscopy and SAXS experiments. Optical textures, typical of the $\mathrm{L}_{\alpha}$ phase, displayed the usual oily streaks separating regions of homeotropic alignment on the glass walls of the flat capillaries (Figure 4a). The SAXS patterns (Figure 5) revealed a series of sharp reflections at q-vector moduli in ratios $1: 2: 3 \ldots$ Since no sharp reflection could be detected at wide angles, X-ray scattering demonstrates that this mesophase is indeed an $\mathrm{L}_{\alpha}$ phase (chains are in a fluid state).

Another birefringent but very turbid phase was also identified in pure Brij30, at $\phi_{\text {Surf }} \sim 10-30 \%$, and also at very low $\phi_{\mathrm{POM}}$, both by polarized light microscopy and SAXS. It is probably the so-called $\mathrm{L}_{\alpha}{ }^{+}$ phase reported previously in the phase diagram of the pure $\mathrm{C}_{12} \mathrm{E}_{4}$ surfactant. ${ }^{10 \mathrm{~b}}$ This phase shows a wispy texture that looks nematic at first sight but is made of tiny oily streaks and focal conics. Moreover, its X-ray scattering pattern displays rather sharp peaks even though they are broader than

those of the usual $\mathrm{L}_{\alpha}$ phase. The $\mathrm{L}_{\alpha}{ }^{+}$phase was interpreted as a textural state of the usual $\mathrm{L}_{\alpha}$ phase ${ }^{10 \mathrm{~b}}$ but still remains somewhat mysterious. Interestingly, we observe that the $\mathrm{L}_{\alpha}{ }^{+}$phase is unstable with respect to the $\mathrm{L}_{\alpha}$ phase upon doping with POMs, even at $\phi_{\mathrm{POM}}$ as low as $\sim 1 \%$. This $\mathrm{L}_{\alpha}^{+}$phase is therefore only found in a very small region of the phase diagram and we will not consider it any further.

Very concentrated mixtures $\left(\phi_{\text {Surf }}>70 \%\right)$ were not investigated because they are too viscoelastic. Moreover, the interlamellar distance may be too small to accommodate the POMs in such concentrated samples. Indeed, at $\phi_{\text {Surf }}=80 \%$, the thickness $(0.8 \mathrm{~nm})$ of the interlamellar space is smaller than the average diameter of the POMs $(1.09 \mathrm{~nm})$. Very dilute samples, at very low $\phi_{\text {Surf, }}$ are biphasic, with a turbid whitish phase at the bottom of the test tubes and a transparent isotropic one at the top. (POMs 
were found in both phases.) The $\mathrm{L}_{\alpha}$ phase, at intermediate dilutions $\left(\phi_{\text {Surf }} \sim 50 \%\right)$, can accommodate in its interlamellar aqueous region, a fairly large volume fraction of POMs, extending easily to more than $4 \%$ and even up to about $8 \%$ for slightly more concentrated samples. (All the samples with $\phi_{\mathrm{POM}}>9 \%$ are biphasic.) Upon larger doping, the system demixes into a slightly turbid, birefringent lamellar phase at the top of the test tubes and an isotropic one at the bottom. (POMs were found in both phases.) The isotropic phase only gives a weak SAXS peak, which hampers its identification as a $\mathrm{L}_{3}$ (sponge) phase or a $\mathrm{L}_{1}$ micellar phase. Altogether, higher $\phi_{\mathrm{POM}}$ can be reached for more concentrated $\mathrm{L}_{\alpha}$ phases; in other words, the maximum $\phi_{\mathrm{POM}}$ is an increasing function of $\phi_{\text {Surf. }}$

We also observed an area ranging from $\phi_{\text {Surf }}=30 \%$ to $\phi_{\text {Surf }}=40 \%$ and $\phi_{\mathrm{POM}}$ from 1.5 to $3.5 \%$, where the $\mathrm{L}_{\alpha}$ phase displays uniform colors in polarized light microscopy and is particularly fluid. This unexpected feature is presently under study.

Similar experiments carried out with pure $\mathrm{C}_{12} \mathrm{EO}_{4}$ instead of Brij30 revealed very similar qualitative features except that the small $\mathrm{L}_{\alpha}{ }^{+}$region was actually not observed (which may be due to the effect of temperature $^{10 \mathrm{~b}}$ ) and that the doping limit of the lamellar phase was reached at smaller $\phi_{\mathrm{POM}}$ (around $2.5 \%$ ). Because of this and because $\mathrm{C}_{12} \mathrm{EO}_{4}$ is much more expensive than Brij30, we decided to use this latter surfactant only, bearing in mind possible applications.

The lamellar period d was measured by SAXS as a function of Brij30 volume fraction at constant $\phi_{\text {POM. }}$ For a homogeneous $\mathrm{L}_{\alpha}$ phase, at moderate swelling, a linear dependence of $\mathrm{d}$ with $1 / \phi_{\text {Surf }}$ is expected (Figure 6) with a slope equal to the membrane thickness $\delta .{ }^{13}$ The value obtained here $3.44 \mathrm{~nm}$ compares rather well with the $3.11 \mathrm{~nm}$ reported for pure $\mathrm{C}_{12} \mathrm{EO}_{4}$ in the literature. ${ }^{14}$

The number and relative intensities of the different orders of lamellar reflections are clearly altered by the doping at constant $\phi_{\text {Surf }}$ (see Figure 5). Upon increasing $\phi_{\mathrm{POM}}$, more reflections are detected and the intensity of the second order strongly increases compared to that of the first. This feature, which will be addressed in detail in the discussion section, proves that the POMs are well dispersed in the lamellar phase, at the microscopic level. 
The clearing temperature $\mathrm{T}_{\mathrm{c}}\left(\mathrm{L}_{\alpha}\right.$ to isotropic liquid transition) of the lamellar phase strongly decreases with increasing doping. For instance, at $\phi_{\text {Surf }}=50 \%, \mathrm{~T}_{\mathrm{c}}=58{ }^{\circ} \mathrm{C}$ at $\phi_{\mathrm{POM}}=4 \%$ whereas it is $\mathrm{T}_{\mathrm{c}}=69{ }^{\circ} \mathrm{C}$ for the undoped phase. This depression of the clearing temperature upon doping with POMs is consistent with the thermodynamic effects of impurity addition. ${ }^{15}$ By slowly cooling samples from the isotropic phase in flat glass capillaries, we were able to grow highly aligned samples in homeotropic orientation that appear quite dark between crossed polarizers (Figure 4b).

Preliminary rheological experiments (to be published elsewhere, in more detail) demonstrate viscoelastic behaviour with $\mathrm{G}$ " $<\mathrm{G}$, G' of the order of a few hundred Pascals, and a yield stress of a few Pascals, for all $\mathrm{L}_{\alpha}$ samples. However, unexpectedly, doping makes the lamellar phase more fluid. The instantaneous elastic modulus $\mathrm{G}_{0}$ changes from $233 \mathrm{~Pa}$ to $182 \mathrm{~Pa}$ upon doping the lamellar phase $\left(\phi_{\text {Surf }}=\right.$ $40 \%$ ) with $\phi_{\mathrm{POM}}=2.5 \%$. At the same time, the viscosity changes from 25.1 Pa.s to 8.4 Pa.s (measured at a constant stress of $20 \mathrm{~Pa})$.

The POM-doped $\mathrm{L}_{\alpha}$ phase is very sensitive to UV-light (and also, to a smaller extent, to natural light,). Indeed, samples exposed to UV-light turn blue, which is the sign of the transformation of the $\left[\mathrm{PW}_{12} \mathrm{O}_{40}\right]^{3-}$ species into reduced species. The hybrid $\mathrm{L}_{\alpha}$ phase is actually much more sensitive to photoreduction than the corresponding POM solution of the same concentration (Figure 7). Hence, the Brij30 surfactant must play a role in this redox reaction. When exposure to UV-light is stopped, the blue color disappears very slowly as dioxygen gradually diffuses from the test tube atmosphere into the sample and reoxidizes the reduced POM species. This reoxidation-induced bleaching can be prevented by carefully purging the test tube atmosphere from dioxygen.

Spectroscopic experiments were performed in order to identify the reduced POM species. The light absorption spectrum of these photochromic compounds (Figure 8) exhibits 3 bands in the visible-near IR range located at $495 \mathrm{~nm}, 750 \mathrm{~nm}$ and $1270 \mathrm{~nm}$. These electronic transitions are close to those reported for one-electron reduced dodecatungstate polyanions. ${ }^{16}$ They can be assigned to d-d transitions and to an intervalence transition respectively. ${ }^{6,16}$ 
The frozen ESR spectrum of the LC-POM hybrid phase, recorded at $6 \mathrm{~K}$ is shown in figure 9 .This ESR spectrum is typical of a W(V) ion in an orthorhombic ligand field and can be described by the following Zeeman Hamiltonian:

$$
H=g_{x} \beta H_{x} S_{x}+g_{y} \beta H_{y} S_{y}+g_{z} \beta H_{z} S_{z}
$$

The main axis of Landé tensor $\mathbf{g}$ is taken along the distortion axis z, i.e., along the $\mathrm{W}=\mathrm{O}$ bond. The magnetic parameters deduced from a computer simulation, using a Gaussian line shape, are $g_{x}=1.825$; $g_{y}=1.818 ; g_{z}=1.784$ (with an accuracy of 0.003 ). A line broadening is observed above $20 \mathrm{~K}$ and a very broad signal is observed above $60 \mathrm{~K}$.

\section{Discussion}

One of the first issues raised by our work is the localization of the POMs within the $\mathrm{L}_{\alpha}$ phase. We know that they are rather homogeneously dispersed because no contrast can be seen by optical microscopy in natural light and because X-ray diffraction patterns (both at small and wide angles) are typical of a common $\mathrm{L}_{\alpha}$ phase. Moreover, the lamellar period doesn't change with the addition of POMs which is a sign that the system is not biphasic, even at the microscopic level. However, the significant change in the lamellar peak relative intensities points to the fact that the POMs are somehow 'organized' inside the $\mathrm{L}_{\alpha}$ phase.

The question of the POMs localization can be addressed by exploiting the integrated intensities of the lamellar reflections which are deeply altered by POM doping. The only information that we can derive relates to the electron density profile $\rho(\mathrm{z})$ along the normal to the layers Oz (Figure 10). Such an approach is actually very classical both for lyotropic lamellar phases of surfactants ${ }^{17}$ and for smectic phases of thermotropic liquid-crystalline polymers. ${ }^{18}$ Since the $\mathrm{L}_{\alpha}$ phase is centrosymmetric, $\rho(\mathrm{z})$ can be expanded in a Fourier series that only involves cosine terms: $\rho(\mathrm{z})=\rho_{\text {ave }}+\sum_{n=1}^{\infty}\left\{ \pm\left|A_{n}\right| \cos \left(\frac{2 \pi n z}{d}\right)\right\}$ 
The Fourier series coefficient $A_{n}$ is proportional to the square root of the integrated intensity of the $n^{\text {th }}$ lamellar reflection. Experimentally, only two or three diffraction orders (with intensities $I_{1}, I_{2}$ and $I_{3}$ ) have been measured from powder-like samples and hence the absolute values (i.e. not their signs) of the coefficients $A_{1}, A_{2}$ and $A_{3}$ were determined. (The powder Lorentz correction $\left(I . q^{2}\right)$ has been applied to the intensities of each peak.)

On the other hand, to determine the sign of each coefficient, we must resort to physical arguments. The expected shape of a typical electron density profile of an undoped lamellar phase is known. In each period, there should be a minimum that corresponds to the low electron density of the paraffinic chains $\left(276 \mathrm{e}^{-} / \mathrm{nm}^{3}\right)$; there should also be two maxima that correspond to the hydrophilic heads $\left(340 \mathrm{e}^{-} / \mathrm{nm}^{3}\right)$ separated by the water region of slightly lower electron density $\left(333 \mathrm{e}^{-} / \mathrm{nm}^{3}\right)$. Some sign combinations are also redundant; we can eliminate half of them by setting the minimum at $\mathrm{z}=0$ (paraffinic chains). For both the undoped and doped lamellar phases, only one sign combination led to reasonable density profiles.

The following two points have also been used: (1) The average electron density $\rho_{\text {ave }}$ of each sample is fixed by its composition, and (2) the electron density at the middle of the paraffinic region at $\mathrm{z}=0$ is fixed at $\rho_{\min }=276 \mathrm{e}^{-/ \mathrm{nm}^{3}}$, which is the accepted value for $\mathrm{C}_{12}$ chains. ${ }^{19}$ Two coefficient ratios are then used for the reconstruction: $A_{21}=\frac{A_{2}}{A_{1}}=+\sqrt{\frac{I_{2}}{I_{1}}}$ and $A_{31}=\frac{A_{3}}{A_{1}}=+\sqrt{\frac{I_{3}}{I_{1}}}$, and $\rho(\mathrm{z})$ can be expressed as: $\rho(\mathrm{z})=\rho_{\text {ave }}+\left(\rho_{\min }-\rho_{\text {ave }}\right)\left(\cos \left(\frac{2 \pi \mathrm{z}}{d}\right)+\mathrm{A}_{21} \cos \left(\frac{4 \pi \mathrm{z}}{d}\right)+\mathrm{A}_{31} \cos \left(\frac{6 \pi \mathrm{z}}{d}\right)\right) /\left(1+\mathrm{A}_{21}+\mathrm{A}_{31}\right)$

In Figure 10a, three reconstructions are compared, with and without POMs $\left(\phi_{\mathrm{POM}}=0,1.7 \%\right.$, and 3.5 $\%)$ at the same Brij30 concentration $\left(\phi_{\text {Surf }}=50 \%\right)$. By construction, at $\mathrm{z}=0$ and $\mathrm{z}=\mathrm{d}=6.9 \mathrm{~nm}$, the two profiles show the same minimum corresponding to the paraffinic chains. Without POMs, the profile shows a small increase of the density around $\mathrm{z}=2 \mathrm{~nm}$ and $\mathrm{z}=4.8 \mathrm{~nm}$, corresponding to the hydrated ethylene oxide groups. In between, at about $\mathrm{z}=3.4 \mathrm{~nm}$, the reconstruction gives a value of the density close to that of pure water $\left(333 \mathrm{e}^{-} / \mathrm{nm}^{3}\right)$. Interestingly, in this intermediate region, and in the presence of 
POMs, the value of the electron density remains close to that of pure water, which is much less than the electron density of the $3.5 \%$ POMs solution $\left(385 \mathrm{e}^{-} / \mathrm{nm}^{3}\right)$. In contrast, a strong increase of the density in the polar-head region is observed (up to $405 \mathrm{e}^{-} / \mathrm{nm}^{3}$ ). This effect is even more important when the POM concentration increases. This strongly suggests that the POMs are mostly located close to the polarheads and interact with the bilayer surface. Our present understanding of the molecular organization of the hybrid lamellar phase is sketched in Figure 10b. Further structural studies are presently under way in our laboratories in order to reach a more precise description of these materials.

A second issue about the behavior of the POMs in the hybrid lamellar phase is the question of their interaction with the surfactant hydrophilic heads. In previous work, the negatively charged POMs were generally associated with cationic surfactants by very strong attractive electrostatic interactions, which sometimes even led to the crystallization of the materials. ${ }^{8 \mathrm{e}}$ This strategy makes use of an ionic selfassembly (ISA) mechanism of oppositely-charged moieties that was also invoked for explaining the formation of mesostructured SBA-type silicas templated by Pluronic block-copolymers. ${ }^{20}$ The POMs are then strongly complexed by the surfactants to the extent that they can sometimes even be extracted and solubilized in organic solvents. In contrast, we associated POMs with nonionic surfactants in an attempt to avoid such strong interactions that may be too specific of a given POM-surfactant pair and that could also have a negative impact on the processability of the hybrid materials. However, our discussion of the electron density profiles proves that there is still an attractive interaction between the POMs anions and the nonionic ethylene-oxide groups. Since the ethylene oxide hydrophilic head of Brij30 is a non-polar nucleophilic moiety, considering any attraction between them and the negatively charged POMs may be a priori surprising. However, this attraction can be mediated by $\mathrm{H}^{+}$cations that are very probably attracted by the ethylene-oxide groups. ${ }^{21}$ These $\mathrm{H}^{+}$cations can in turn attract the POMs at the bilayer surface, which can explain why a rather large amount of POMs can be inserted into the lamellar $\mathrm{L}_{\alpha}$ phase. Such considerations mean that the interaction between membranes would shift 
from a Helfrich-type entropic repulsion ${ }^{22}$ to a more efficient electrostatic one if the bilayers bear some charge excess.

Another interesting feature of this hybrid composite system is that it readily turns blue when exposed to UV light. This photochromic behavior has been studied via ESR and UV visible spectroscopies. The $g$ values found for these light-irradiated LC-POM hybrid materials can be plotted in a $g_{z}$ versus $\left(\left(g_{x}+g_{y}\right) / 2\right)$ diagram together with reported values for different families of one-electron reduced polyoxotungstate anions (figure 12). ${ }^{6,16,23}$ The ESR parameters of the photo-reduced polyanion clearly range in the domain found for dodecatungstates polyanions. ${ }^{16,24}$ The ESR line broadening observed at low temperatures is due to a hopping of the unpaired electron between $\mathrm{W}^{\mathrm{V}}$ and $\mathrm{W}^{\mathrm{VI}}$ ions. Such a hopping occurs via tunneling at very low temperatures $(20 \mathrm{~K})$ and can be thermally activated through the vibrations of the polyanions at higher temperatures $(60 \mathrm{~K}) .{ }^{16,23}$ Moreover a strong intervalence band transition is observed at lowest energy $(1270 \mathrm{~nm})$. All these electronic and magnetic features are characteristic of the mixed-valence properties of one-electron reduced tungsten polyanions. These data clearly demonstrate that the structure of the $\left[\mathrm{PW}_{12} \mathrm{O}_{40}\right]^{4-}$ polyanion is conserved after irradiation and that the intense blue color corresponds to the optically activated transfer occurring in mixed-valence oneelectron reduced phosphododecatungstates polyanions.

Assuming that one-electron reduced $\left[\mathrm{PW}_{12} \mathrm{O}_{40}\right]^{4-}$ polyanions are the only species formed upon UVlight irradiation, the electronic data (optical density of the d-d transitions and molar coefficients of extinction reported in the literature) allow us to estimate the molar concentration of reduced polyoxometalates. It reaches 5 molar \% after 5 minutes, 13 molar \% after 10 minutes and 33 molar \% after 45 minutes of irradiation. This non-linear relation observed at high concentration of reduced species is possibly due to transmission losses resulting from the very strong absorption of the reduced polyoxometalates. The strong coloration is stable when the hybrid material is kept under nitrogen atmosphere. However, in the presence of air, the reduced polyoxometalate anions are back-oxidized by dioxygen in agreement with previously reported studies. ${ }^{25}$ 
The photo-assisted reduction of $\mathrm{W}^{\mathrm{VI}}$ to $\mathrm{W}^{\mathrm{V}}$ is most probably coupled with the oxidation of the alcoholic polar groups of the Brij30 surfactants which are therefore transformed into carbonylated (aldehydes or carboxylates) species. Indeed, the photochemical reduction of alcohols by $\mathrm{H}_{3} \mathrm{PW}_{12} \mathrm{O}_{40}$ is well documented and should occur as well in this context. ${ }^{26}$ Infrared and Raman studies are in progress to determine the nature of the oxidized organic moieties.

\section{Conclusions}

Up to about 10 vol. $\%\left[\mathrm{PW}_{12} \mathrm{O}_{40}\right]^{3-}$ ions could be successfully incorporated into the aqueous regions of the $\mathrm{L}_{\alpha}$ phase of the nonionic surfactant Brij30. The resulting composite material combines the viscoelasticity and anisotropic properties typical of liquid crystals and the chemical properties of polyoxometalates. The POMs are homogeneously dispersed within the mesophase and the exploitation of the lamellar reflection intensities suggest that the POMs are partially adsorbed onto the polyethyleneglycol brushes that coat the surfactant membranes. The doped $\mathrm{L}_{\alpha}$ phase readily turns blue when exposed to UV light; it is more sensitive than a POM solution at the same concentration. It is also much more viscoelastic, with rheological properties close to those of gels. Such properties may be interesting for applications involving UV-light absorption coatings. Moreover, very well aligned samples of the POM-doped $\mathrm{L}_{\alpha}$ phase could be produced. The association of the POMs with the nonionic surfactant membranes does not result from the ionic self-assembly mechanism previously used by other groups to design POM-based hybrid materials but could be mediated by $\mathrm{H}^{+}$cations. This process can naturally be extended to other nonionic surfactants to control the mesophase type and stability and to other kinds of POMs to exploit other electronic properties. From a more fundamental point of view, these samples will prove very useful in studying both the static and dynamic properties of the POMs, 2dimensionnally confined within a soft lamellar structure. 
ACKNOWLEDGMENT. We thank S.Rouzière and L.Binet for help with the X-ray scattering and ESR experiments respectively, and one of the Reviewers for helpful remarks about the physical interactions and photochemical reactions between the Brij30 hydrophilic headgroups and $\mathrm{H}_{3} \mathrm{PW}_{12} \mathrm{O}_{40}$. A. P. acknowledges support from a Marie Curie Action (No. MEST-CT-2004-514307).

\section{FIGURE CAPTIONS.}

Figure 1: a) Chemical formula of the Brij30 nonionic surfactant. b) Representation of the $\mathrm{PW}_{12} \mathrm{O}_{40}{ }^{3-}$ polyoxometallate. This heteropolyanion of Keggin structure has a phosphorus atom in tetrahedral coordination at its center, surrounded by twelve $\mathrm{WO}_{6}$ octahedra arranged in four groups of three edgeshared octahedra. These triplets are linked together by sharing corners and are also linked to the central $\mathrm{PO}_{4}$ tetrahedron.

Figure 2: Phase diagram of the $\left(\mathrm{Brij} 30-\mathrm{H}_{2} \mathrm{O}-\left[\mathrm{PW}_{12} \mathrm{O}_{40}\right]^{3-}\right)$ hybrid system represented as a function of the overall surfactant volume fraction, $\phi_{\text {surf, }}$ and the POMs volume fraction in the aqueous medium, $\phi_{\mathrm{POM}}$. The solid circles, solid triangles, and open circles represent the $\mathrm{L}_{\alpha}$ phase, the $\mathrm{L}_{\alpha}^{+}$phase, and the biphasic region, respectively.

Figure 3: Photographs of test-tubes (a) in natural light and (b) in polarized light of a series of samples at constant surfactant concentration $\left(\phi_{\text {surf }}=50 \%\right)$ and increasing POM doping (from left to right, $\phi_{\mathrm{POM}}=$ $0 \%, 1.7 \%, 3.5 \%$, and $8.3 \%$ ). The arrow points to the meniscus between the two phases in the biphasic sample at $\phi_{\mathrm{POM}}=8.3 \%$.

Figure 4: Observations by polarized light microscopy of the textures of the same capillary $\left(\phi_{\text {surf }}=50 \%\right.$, $\phi_{\mathrm{POM}}=3.5 \%$ ) before (a) and after (b) heat treatment. The overall dark appearance of the sample after heat treatment shows that most lamellae are aligned parallel to the flat faces of the capillary. A faint area of parabolic focal conics persists at the center of the sample. The homeotropic orientation is lost at the edges of the capillary, which shows that the phase is actually $\mathrm{L}_{\alpha}$. The width of the capillary is $1 \mathrm{~mm}$. 
Figure 5: Evolution of the SAXS patterns, at fixed surfactant concentration $\phi_{\text {surf }}=50 \%$, upon increasing POM doping (a) $\phi_{\mathrm{POM}}=0 \%$, (b) $\phi_{\mathrm{POM}}=1.7 \%$, and (c) $\phi_{\mathrm{POM}}=3.5 \%$. The ratios of the second and third to first lamellar peak integrated intensities are: (a) 0.14 and $\sim 0$, (b) 0.7 and $\sim 0$, (c) 2.2 and 0.02 .

Figure 6: Dilution law, $d$ versus $\phi_{\text {Surf, }}$ of the Brij30 $L_{\alpha}$ lamellar phase. A linear fit, $d=\delta / \phi_{\text {Surf, }}$ provides the width of the bilayer: $\delta=3.4 \mathrm{~nm}$.

Figure 7: Photographs of two test-tubes filled with (left) a solution of POMs and (right) the doped lamellar phase, at the same POM concentration (1.7\%), recorded after UV-light exposure for (a) 0 min, (b) 15 mins, and (c) 60 mins.

Figure 8: Visible and near-infrared spectra of a doped lamellar phase $\left(\phi_{\text {Surf }}=50 \%, \phi_{\mathrm{POM}}=3.5 \%\right)$ after UV irradiation. Curves (a), (b) and (c) are from samples irradiated for 5, 10 and 45 minutes respectively.

Figure 9: ESR spectrum of a doped lamellar phase, of composition $\phi_{\text {surf }}=50 \%$ and $\phi_{\text {POM }}=3.5 \%$, recorded at $6 \mathrm{~K}$. The dashed line shows the best fit to the spectrum.

Figure 10: (a) Electronic density reconstruction based on lamellar peak integrated intensities for three samples with $\phi_{\text {Surf }}=50 \%$. The black, dark grey and light grey curves correspond to $\phi_{\mathrm{POM}}=0 \%, 1.7 \%$ and 3.5\%, respectively. The horizontal lines represent the electronic densities of water $\left(334 \mathrm{e}^{-} / \mathrm{nm}^{3}\right)$ and of a POM solution with $\phi_{\mathrm{POM}}=3.5 \%\left(385 \mathrm{e}^{-/ \mathrm{nm}^{3}}\right)$. (b) Tentative sketch (to scale) of the molecular organization of the POM-doped lamellar $\mathrm{L}_{\alpha}$ phase. The aqueous medium is represented in light blue and the hydrophobic membranes are shown in light yellow. The $\mathrm{C}_{12}$ paraffinic chains are depicted in dark yellow and the $\mathrm{EO}_{4}$ chains are in red.

Figure 11: Diagram $g_{z}$ vs. $(1 / 2)\left(g_{x}+g_{y}\right)$ for one-electron reduced polytungstates:

$(\diamond)\left(\mathrm{W}_{6} \mathrm{O}_{19}\right)^{3-}$ and $\left(\mathrm{W}_{5} \mathrm{NbO}_{19}\right)^{4-} ;(\star)\left(\mathrm{XW}_{12} \mathrm{O}_{40}\right)^{\mathrm{n}-} ;(\boldsymbol{O})\left(\mathrm{XW}_{18} \mathrm{O}_{62}\right)^{\mathrm{n}-} ;(\boldsymbol{\square})($ this study $)$ 
(a)<smiles>CCCCCCCCCCCC[Te]CC[GeH2]O</smiles>

(b)

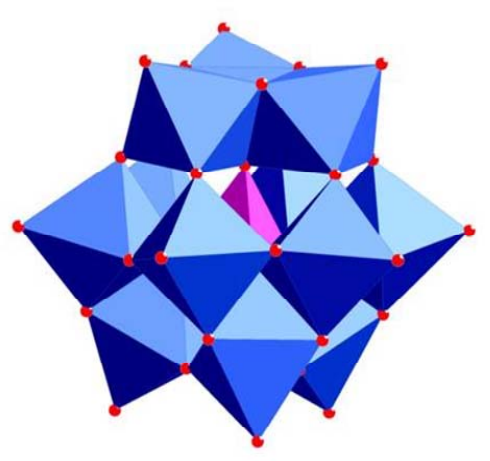

Figure 1

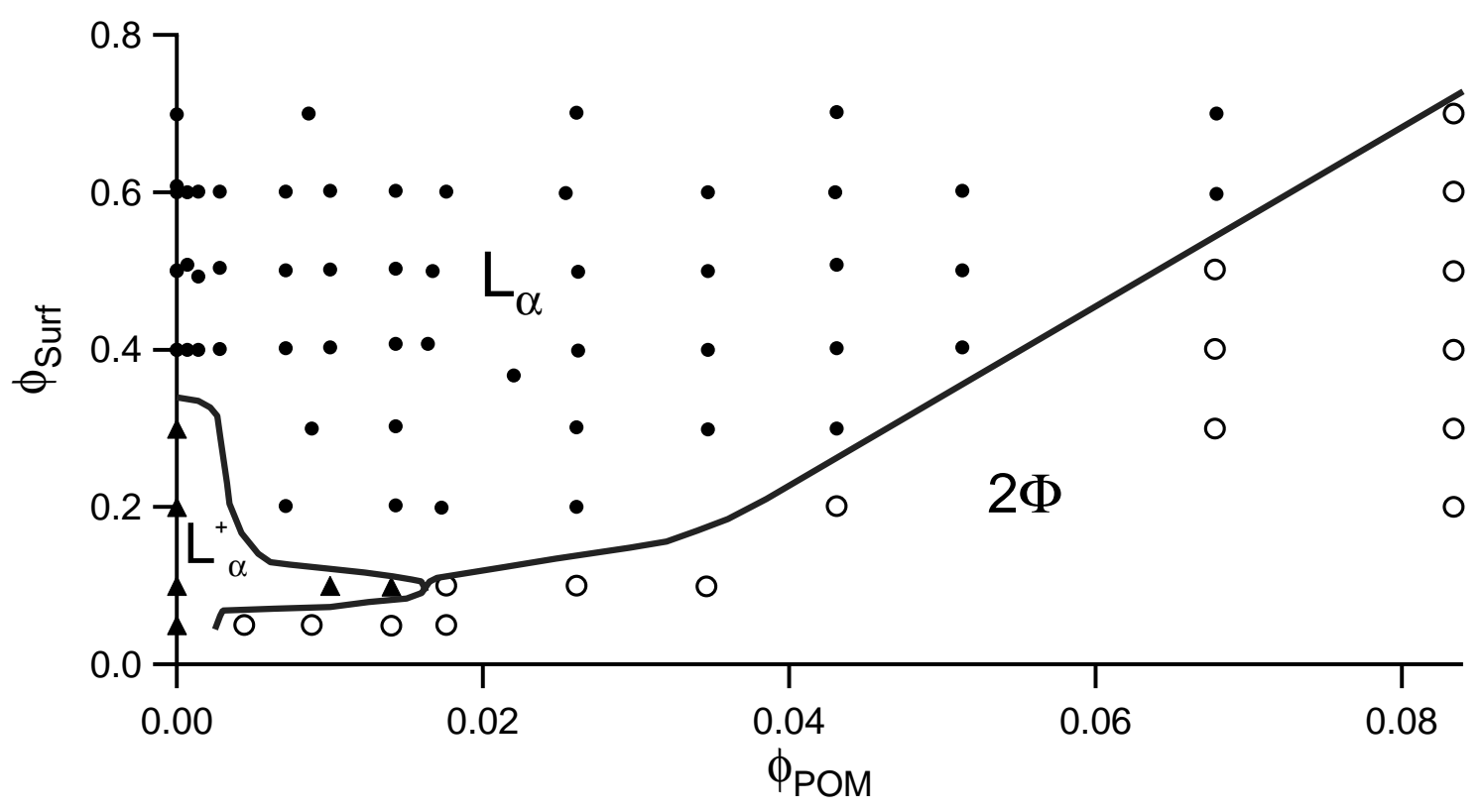

Figure 2 


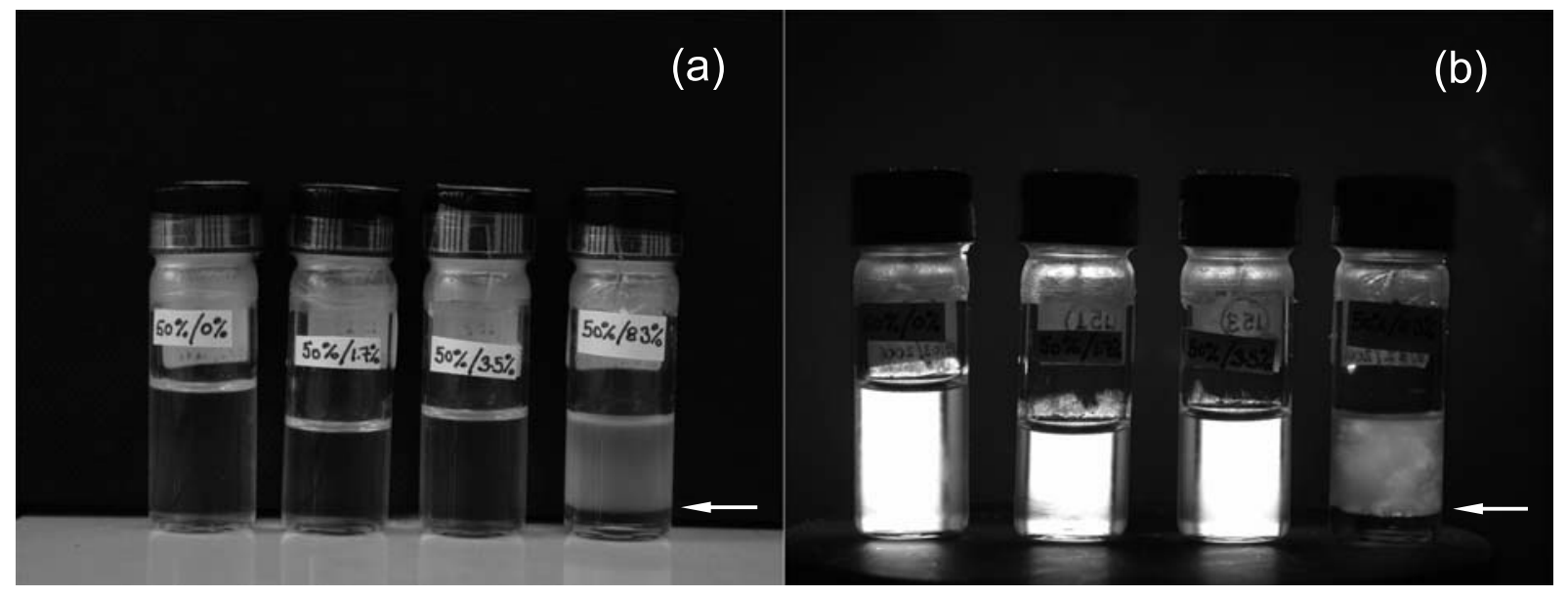

Figure 3

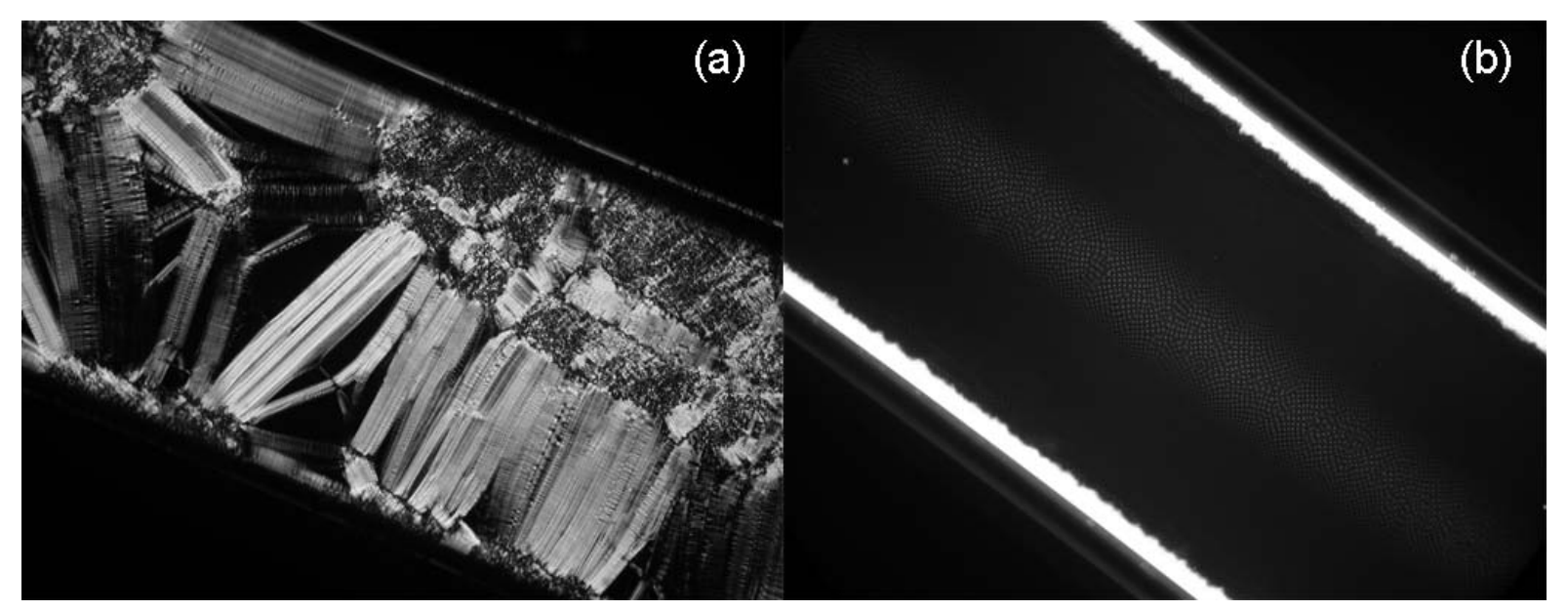

Figure 4 

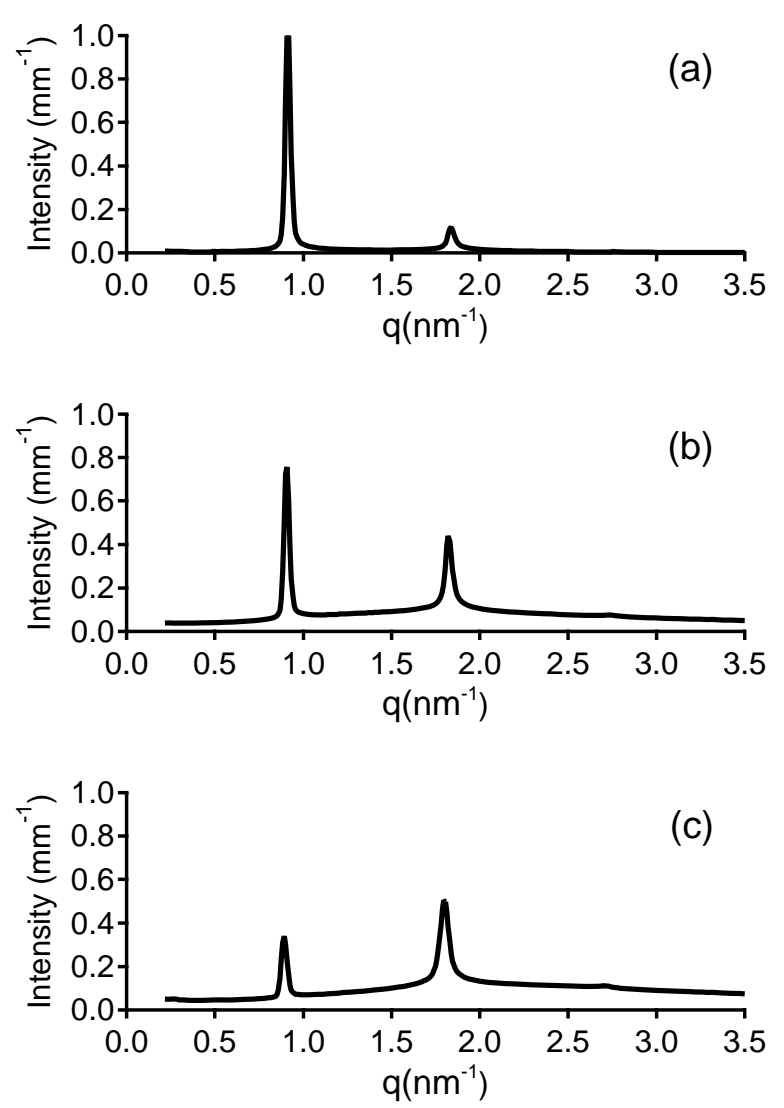

Figure 5

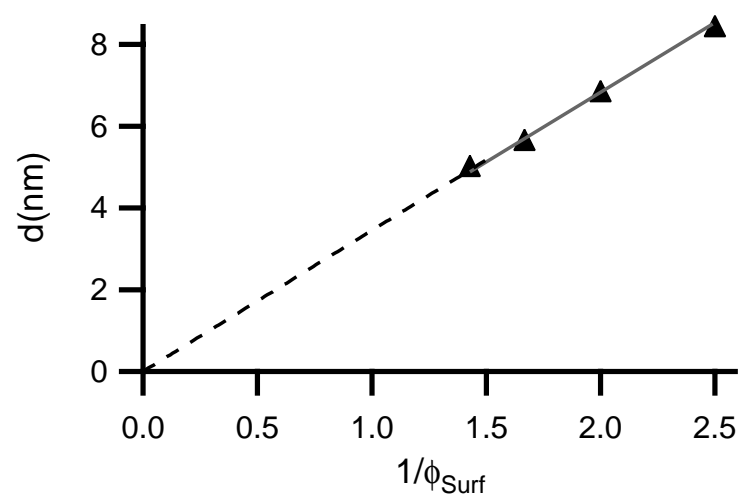

Figure 6 


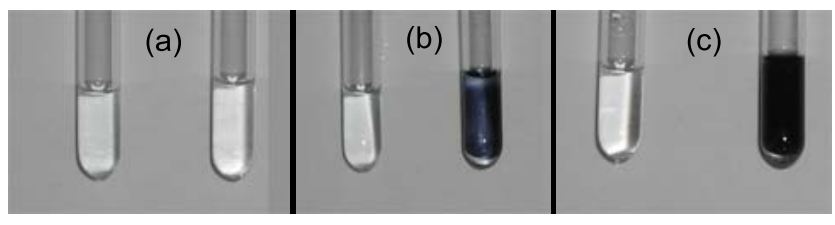

Figure 7

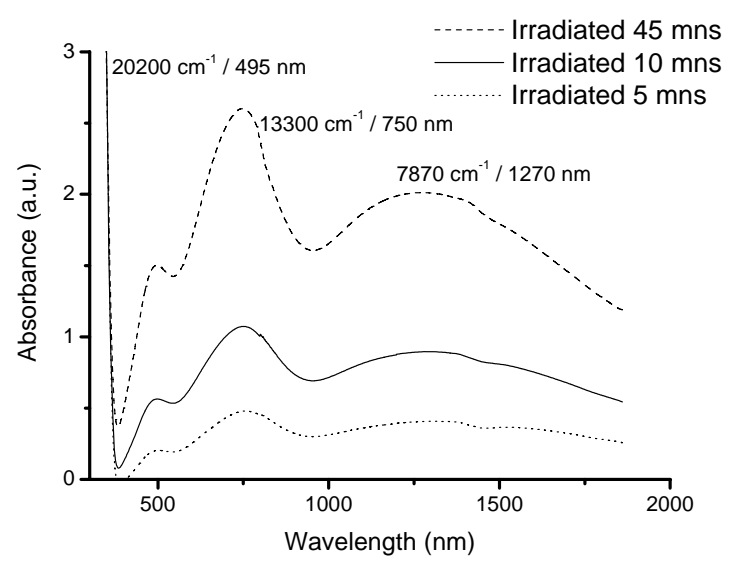

Figure 8

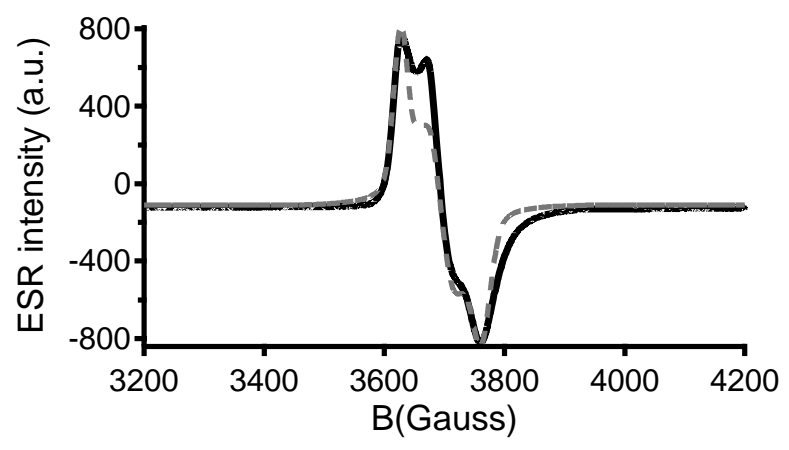

Figure 9 
b)
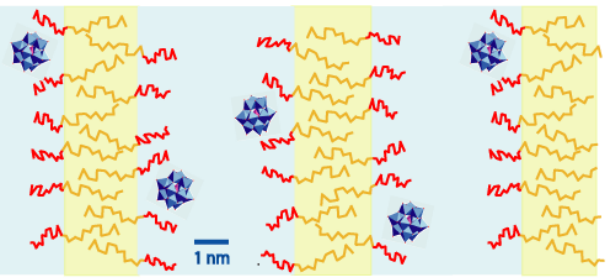

a)

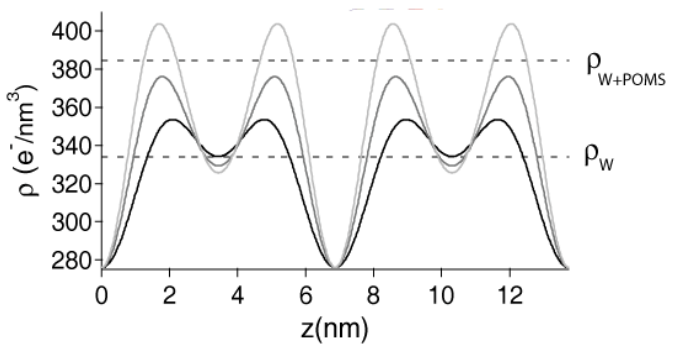

Figure 10

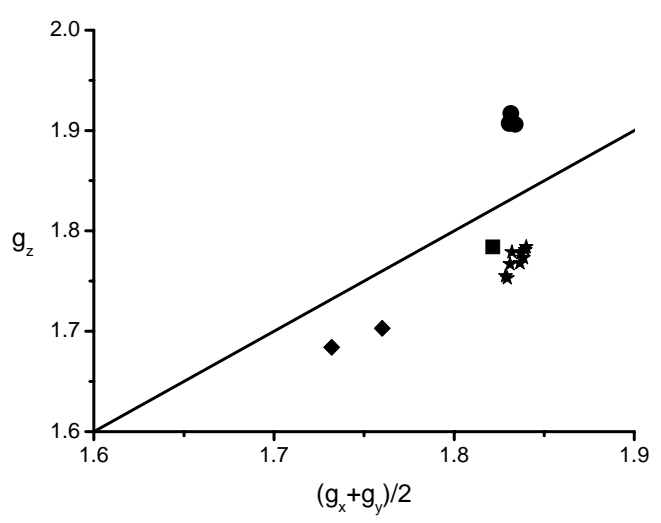

Figure 11 


\section{REFERENCES}

(1) (a) Sanchez, C.; Soler-Illia, G.J.D.A.; Ribot, F.; Lalot, T. ; Mayer, C.R.; Cabuil, V. Chemistry of Materials 2001, 13, 3061-3083 (b) Kickelbick, G. Progress in Polymer Science 2003, 28, 83-114. (c) Kickelbick, G. Angew. Chem. Int. Ed. 2004, 43, 3102-3104. (d) Functional Hybrid Materials; GómezRomero, P., Sanchez, C., Eds; Wiley-VCH: Weinheim, Germany, 2003.

(2) Sanchez, C.; Julian, B.; Belleville, P.; Popall, M. J. Mat. Chem. 2005, 15, 3559-3592.

(3) Sanchez, C.; Arribart, H.; Giraud-Guille, M.M. Nature Materials 2005, 4, 277-288.

(4) (a) Beck, J. S.; Vartuli, J. C.; Roth, W. J.; Leonowicz, M. E.; Kresge, C. T.; Schmitt, K. T.; Chen, C. T.; Olson, D. H.; Sheppard, E. W.; McCullen, S. B.; Higgins, J. B.; Schlenker, J. L. J. Am. Chem. Soc. 1992, 114, 10834-10843. (b) Zhao, D.; Feng, J.; Huo, Q.; Melosh, N.; Fredrickson, G.; Chmelka, B.; Stucky, G. D. Science 1998, 279, 548-552. (c) Soler-Illia, G.J.D.; Sanchez, C.; Lebeau, B.; Patarin, J. Chem. Rev. 2002, 102, 4093-4138. (d) Brinker, C.J.; Dunphy, D.R. Curr. Opin. Coll. Interf. Sci. 2006, 11, 126-132. (e) Soler-Illia, G.J.A.A.; Innocenzi, P. Chemistry: a European Journal 2006, 12, 44784494. (f) Hoffmann, F.; Cornelius, M.; Morell, J.; Fröba, M. Angew. Chem. Int. Ed. 2006, 45, 32163251.

(5) Sanchez, C.; Boissière, C.; Grosso, D.; Laberty, C.; Nicole, L. Chemistry of Materials, in press.

(6) (a) Pope, M.T.; Müller A. Angewandte Chemie 1991, 30, 34-48. (b) Katsoulis, D.E. Chem. Rev. 1998, 98, 359-387. (c) Gouzerh, P.; Proust, A. Chem. Rev. 1998, 98, 77-111.

(7) (a) Polarz, S.; Smarsly, B.; Göltner, C.; Antonietti, M. Advanced Materials 2000, 12, 1503-1507. (b) Freund, M.S.; Karp, C.; Lewis, N.S. Inorg. Chim. Acta. 1995, 240, 447-451. (c) Judenstein, P.; Schmidt, H. J. Sol-gel Sci. Tech. 1994, 3, 189-197. 
(8)(a) ClementeLeon, M; Agricole, B.; Mingotaud, C.; GomezGarcia, C.J.; Coronado, E.; Delhaes, P. Langmuir 1997, 13, 2340-2347. (b) ClementeLeon, M.; Mingotaud, C.; Agricole, B.; GomezGarcia, C.J.; Coronado, E.; Delhaes, P. Angew. Chem. 1997, 36, 1114-1116. (c) Polarz, S.; Smarsly, B.; Antonietti, M. ChemPhysChem 2001, 7, 457-461. (d) Zhang, T.; Spitz, C.; Antonietti, M.; Faul, C.F.J. Chem. Eur. J. 2005, 11, 1001-1009. (e) Nyman, M.; Ingersoll, D.; Singh, S.; Bonhomme, F.; Alam, T.M.; Brinker, C.J; Rodriguez, M.A. Chemistry of Materials 2005, 17, 2885-2895. (f) Li, W.; Bu, W.; Wu, L., Li, M. Chem. Com. 2005, 3785-3787. (g) Li, W.; Yi, S.; Wu, Y.; Wu, L. J. Phys. Chem. B 2006, 110, 16961-16966. (h) Sun, H.; Li, H.; Bu, W.; Xu, M.; Wu, L. J. Phys. Chem. B 2006, 110, $24847-$ 24854. (i) Moriguchi, I.; Orishikida, K.; Tokuyama, Y.; Watabe, H.; Kagawa, S.; Teraoka, Y. Chemistry of Materials 2001, 13, 2430-2435. (j) Li, W.; Yin, S.; Wang, J.; Wu, L. Chemistry of materials 2008, 20, 514-522.

(9) Keggin, J.F. Nature 1933, 131, 908-909.

(10) (a) Mitchell, D.J.; Tiddy, G.J.T.; Waring, L.; Bostock, T.; Mc Donald, M.P. J. Chem. Soc. Faraday Trans I 1983 79, 975-1000. (b) Strey, R. Ber. Bunsenges. Phys. Chem. 1996, 100, 182-189.

(11) Impéror-Clerc, M.; Davidson, P. Eur. Phys. J. B 1999, 9, 93-104.

(12) Narayanan, T.; Diat, O.; Bösecke, P. Nucl. Instrum. Methods Phys. Res. Sect. A 2001, 467, $1005-$ 1009.

(13) Roux, D.; Safinya, C.R. J. Phys. France 1988, 49, 307-318.

(14) Kurtisovski, E.; Taulier, N.; Ober, R.; Waks, M.; Urbach, W. Phys. Rev. Lett. 2007, 98, $258103-$ 1-4.

(15) Oswald, P.; Pieranski, P. Nematic and cholesteric liquid crystals; CRC Press, Taylor and Francis Group: Boca Raton, FL, USA, 2005; Chapter B IX, p 556. 
(16) Sanchez, C.; Livage, J.; Launay, J.P.; Fournier, M. J. Am. Chem. Soc. 1983, 105, 6817-6823.

(17) Zantl, R.; Artzner, F.; Rapp, G.; Rädler, J.O. Europhys. Lett. 1999, 45, 90-96.

(18) Noirez, L.; Davidson, P.; Schwartz, W.; Pepy, G. Liquid Crystals 1994, 16, 1081-1092.

(19) Zeng, X.; Liu, Y.; Impéror-Clerc, M. J. Phys. Chem. B 2007, 111, 5174-5179.

(20) Zhao, D.; Huo, Q.; Feng, J.; Chmelka, B.F.; Stucky, G.D. J. Am. Chem. Soc. 1998, 130, 60246036.

(21) Alexandridis, P.; Holzwarth, J.F. Langmuir 1997, 13, 6074-6082.

(22) Helfrich, W. Z. Naturforsch. 1978, 33a, 305-315.

(23) Sanchez, C.; Livage, J.; Launay, J.P.; Fournier, M.; Jeannin, Y. J. Am. Chem. Soc. 1982, 104, 3194-3202.

(24) Varga, G.M.; Papaconstantinou, E.; Pope, M.T. Inorg. Chem. 1970, 9, 662-667.

(25) Weinstock, I.A. Chem. Rev. 1998, 98, 113-170.

(26) (a) Hill, C.L.; Bouchard, D.A. J. Am. Chem. Soc. 1985, 107, 5148-5157. (b) Papaconstantinou, E.; Dimotikali, D.; Politou, A. Inorganica Chimica Acta 1980, 43, 155-158. (c) Dimotikali, D. ; Papaconstantinou, E. Inorganica Chimica Acta 1984, 87, 177-180. 